\title{
Juvenile survival and population structure of blue wildebeest and warthogs in the Central Region of the Kruger National Park during the mid-summer drought of 1988/89
}

\author{
D.R. MASON
}

Mason, D.R. 1990. Juvenile survival and population structure of blue wildebeest and warthogs in the Central Region of the Kruger National Park during the midsummer drought of 1988/89. - Koedoe 33(1): 29-45. Pretoria. ISSN 0075-6458.

\begin{abstract}
The survey was undertaken to investigate juvenile survival and population structure of blue wildebeest and warthogs during a mid-summer drought, and to gain supplementary data for a longer-term population monitoring programme. The percentage of adult wildebeest cows with juveniles was lower than normal for the time, but was not commensurate with a sharp decline in the population. Warthogs did not tolerate the drought as well as wildebeest and experienced a larger reduction in juvenile recruitment, albeit much less than the $80-90 \%$ losses of piglets recorded in the more severe drought of late 1982.
\end{abstract}

Key words: juvenile survival, population structure, blue wildebeest, warthogs, midsummer drought.

D.R. Mason, Kruger National Park, Private Bag X402, Skukuza, 1350 Republic of South Africa.

\section{Introduction}

Wildebeest Connochaetes taurinus (Burchell, 1823) in the Kruger National Park (KNP) are most numerous in the $5517 \mathrm{~km}^{2}$ area of the Central Region between the Sabie and Olifants rivers, which comprises $28,4 \%$ of the total area of the KNP. Aerial counts of wildebeest and warthogs Phacochoerus aethiopicus (Pallas, 1766) in the Central Region during the 1988 dry season were 9650 and 1372 respectively, representing $67,4 \%$ and $44,0 \%$ of the total counts for the KNP (Whyte \& Viljoen 1988).

The birth seasons of warthogs and wildebeest in the KNP partly overlap with warthog births usually commencing in late October or early November and ceasing in December, whereas wildebeest usually start slightly later in November or early December and most cows have calved by the end of January. Parturition thus coincides with the wet season in the KNP, which receives $85 \%$ of annual precipitation between October and March during the hot, humid summer, when temperatures frequently exceed $40^{\circ} \mathrm{C}$. In the Central Region mean annual rainfall is between about $500 \mathrm{~mm}$ and $600 \mathrm{~mm}$ and decreases from south to north and from west to east. Moreover, rainfall alternates between wet and dry cycles, each of approximately 10 years. The magnitude of this cyclical variation in mean annual rainfall in the KNP is about $26 \%$ (Gertenbach 1980). Periodic droughts are thus a feature of the climatic regime and typically resulted in large concentrations of game around sparse perennial 
water sources and very low biomass in extensive waterless areas, circumstances which were used to justify the systematic provision of artificial water points throughout the KNP (Joubert 1986). Winter months are predominantly dry and mild to cool with intermittent cold fronts penetrating from the south, but temperatures seldom attain freezing point. Natural attributes of the KNP have been extensively described and include climate and vegetation (Gertenbach 1980, 1983; Venter \& Gertenbach 1986), geomorphology and drainage (Venter \& Bristow 1986), geology (Schutte 1986), and soils (Venter 1986).

During the 1970 s when rainfall in the KNP was predominantly above-average, the wildebeest population of the Central Region declined by more than half. In the subsequent dry cycle of the 1980 s wildebeest numbers recovered and reached a peak of 9951 in 1987. Below-average rainfall cycles favour wildebeest population expansion via changes in habitat condition (Whyte 1985; Whyte \& Joubert 1988). Wildebeest are also more tolerant of drought because of their mobility than relatively sedentary herbivores like warthogs, unless the latter have home ranges with adequate rhizomatous forage from certain grasses. However, drought-associated mortality of juveniles can be very high in both wildebeest and warthogs (Child 1972; Hillman \& Hillman 1977; Mason 1984), and drought effects on wildebeest can be greatly aggravated by fences that restrict their seasonal movements (Williamson \& Mbano 1988). In the 1982/83 wet season, rainfall in the Central Region was particularly low (averaging $55,9 \%$ of the long-term annual mean for the four available recording stations) and was associated with decreases of $6,7 \%$ and $39,9 \%$ in the 1983 aerial counts of wildebeest and warthogs respectively.

During the 1988/89 wet season in the KNP, the first widespread spring rains ( $>15$ $\mathrm{mm}$ ) were spread over three days of drizzling, cold and windy weather from 11-13 October. At Satara camp in the Central Region minimum and maximum temperatures on 10 October were $20,9^{\circ} \mathrm{C}$ and $38,0^{\circ} \mathrm{C}$ but had declined to $13,0^{\circ} \mathrm{C}$ and $17,0^{\circ} \mathrm{C}$ two days later, when a wind speed of 7,0 m/sec. was registered at 08:00. This sudden onset of cold, wet weather triggered limited mortality of herbivores in certain areas, whereas warthogs found shelter in burrows and, notwithstanding some that were in poor physical condition and a single recorded carcass, were not subject to a die-off. No deaths attributable to exposure and/or poor condition were recorded among wildebeest.

Subsequent farrowing and calving during the 1988/89 season coincided with unusually dry conditions over large portions of the Central, Northern and Far-Northern Regions of the KNP, where follow-up rains were patchy or variably sustained and virtually failed in January, which in 1989 was one of the driest on record. Of the four recording stations in the Central Region, Kingfisherspruit experienced zero rainfall in January, Satara was the driest since 1934 with only $1,0 \mathrm{~mm}$, while deficits at Nwanetsi and Tshokwane were similarly massive (Table 1). The failure of the rains in middle summer of 1988/89 continued a phase of predominantly below-average rainfall since the start of the nineteen-eighties. These circumstances were opportune for investigating and comparing the effects of summertime drought on survival of recently recruited juveniles of wildebeest and warthogs, and on their population structure.

\section{Methods}

Sex and age classifications of wildebeest and warthogs were conducted from a vehicle from 1-9 February 1989, traversing over $2000 \mathrm{~km}$ in representative areas of the Central Region. In order to ensure random sampling, every effort was made to count and classify all groups and individuals 


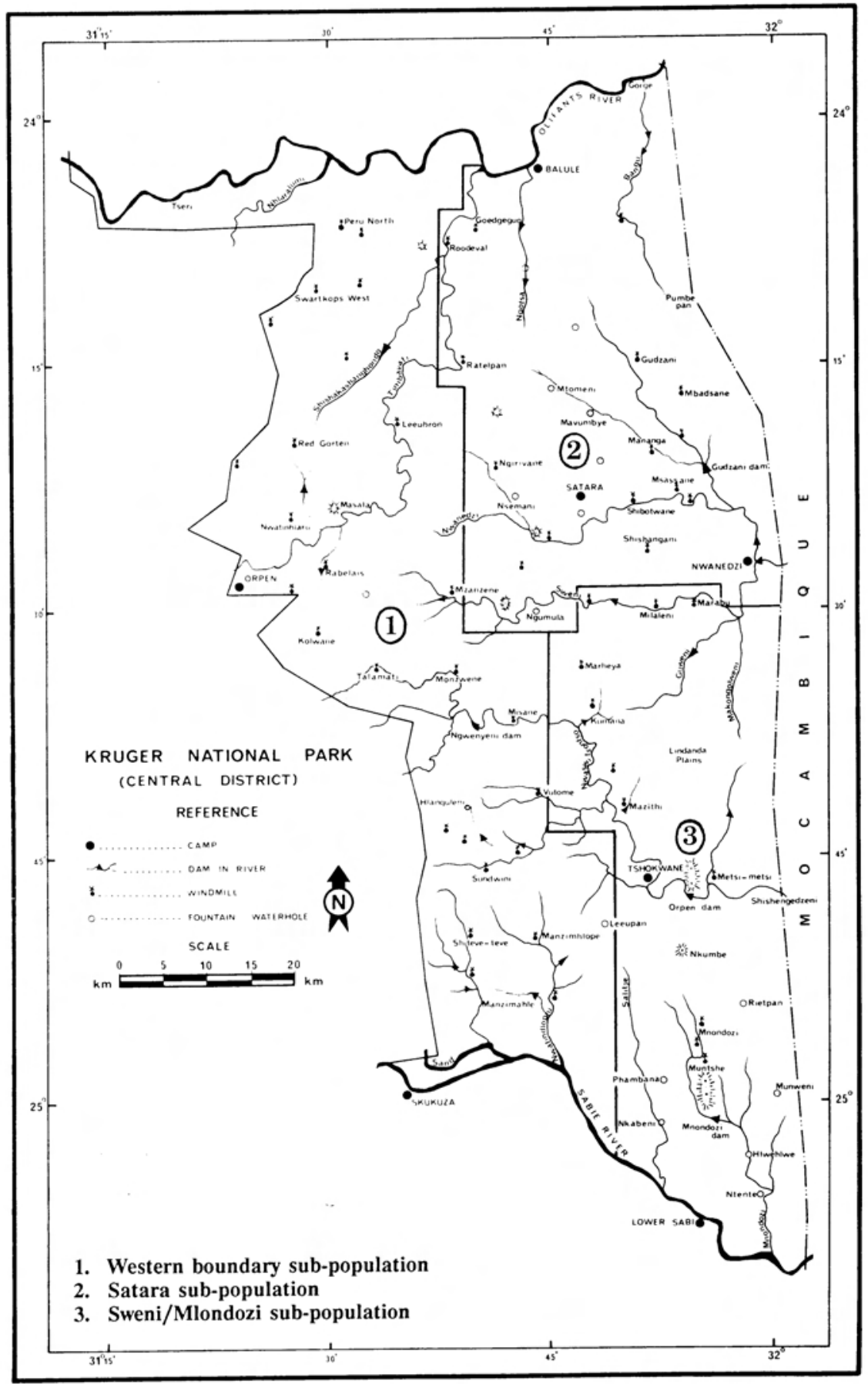

Fig. 1 The boundaries between the three sub-populations of wildebeest in the Central Region of the Kruger National Park (from Whyte 1985). 
encountered. Wildebeest herds were often approached more closely or followed up by driving off roads. Identification of sexes and age classes was facilitated by the use of $8,5 \times 44$ binoculars and a $15-60 \times 60 \mathrm{~mm}$ zoom telescope.

Three age classes, viz. juveniles (0-12 months), yearlings (12-24 months) and adults (over 24 months), were distinguished in both wildebeest and warthogs. Regular sex differentiation of yearling wildebeest was not feasible, especially in larger milling herds. Sex differentiation of juveniles was not attempted with wildebeest, and was not always feasible with warthogs.

Localities of all wildebeest sightings were noted in relation to the ranges of three relatively discrete sub-populations (Fig. 1) described by Whyte (1985) whose data are used for comparing population dynamics. Supplementary data on population parameters and trends of both wildebeest and warthogs are derived from standardised ground surveys of ungulate populations throughout the KNP, conducted annually during August-October since 1983 (Mason 1984, 1985, 1986, 1987, 1988,1989 ), and standardised aerial counts, conducted annually during the dry season (Viljoen 1989).

Ninety-five per cent confidence intervals were calculated for the data on juvenile/adult female ratios of wildebeest and warthogs using statistical procedures described by the Wyoming Game \& Fish Department (1977) and expressed by the equation:

$$
\mathrm{b}=(\mathrm{a}+100 \mathrm{t}) 10^{-1} \cdot\left[\mathrm{a}\left(\mathrm{n}^{-1}-\mathrm{N}^{-1}\right]^{1 / 2}\right.
$$

where $\mathrm{a}=$ estimated number of juveniles per 100 adult females

$\mathrm{b}=$ confidence interval

$\mathrm{t}=$ Student's t-statistic at desired confidence level

$(\mathrm{t} \infty$ d.f. $=1,960$ at 0,05 probability level $)$

$\mathrm{n}=$ sample size of adult females plus juveniles

$\mathrm{N}$ = estimated number of adult females plus juveniles in population

Although the technique requires an estimate of population size, the equation is "generally not sensitive to error in population size estimate" (Wyoming Game \& Fish Department, op. cit.). Population estimates of wildebeest and warthogs in the Central Region of KNP were therefore based on the aerial counts, notwithstanding uncertainties about their accuracy and repeatability. However, because aerial censuses conducted over areas of comparable and denser vegetative cover in the Hluhluwe-Umfolozi Game Reserve were subject to substantial undercounting bias for warthogs (Melton 1978; Brooks 1978; Brooks \& Macdonald 1983), the aerial counts of warthogs in the Central Region have been multiplied by a correction factor of 2,0.

\section{Results and discussion}

Accurate counting and classification of wildebeest was not possible in only three instances (involving breeding herds of about 15-20 individuals) out of a total of 272 observations of these animals. Similarly, circumstances disallowed accurate recording of group size and composition in two out of 100 observations of warthogs. These inconclusive records were omitted from the samples of wildebeest and warthog population structure.

\section{Wildebeest}

The overall population sample of 2549 wildebeest from the Central Region during February 1989 included 39,0\% breeding groups, 45,0\% lone adult males and 14,5 $\%$ bachelor groups (Table 2). In the Sweni/Mlondozi sub-population which unlike the other two has retained a traditional seasonal movement cycle, most of the breeding herds encountered were on the knobthorn-marula savanna plains in the Nkumbe and Lindanda areas. The largest bachelor herd numbered 56 (all adult males) and was recorded near the Mananga windpumps within the range of the Satara sub-population. 


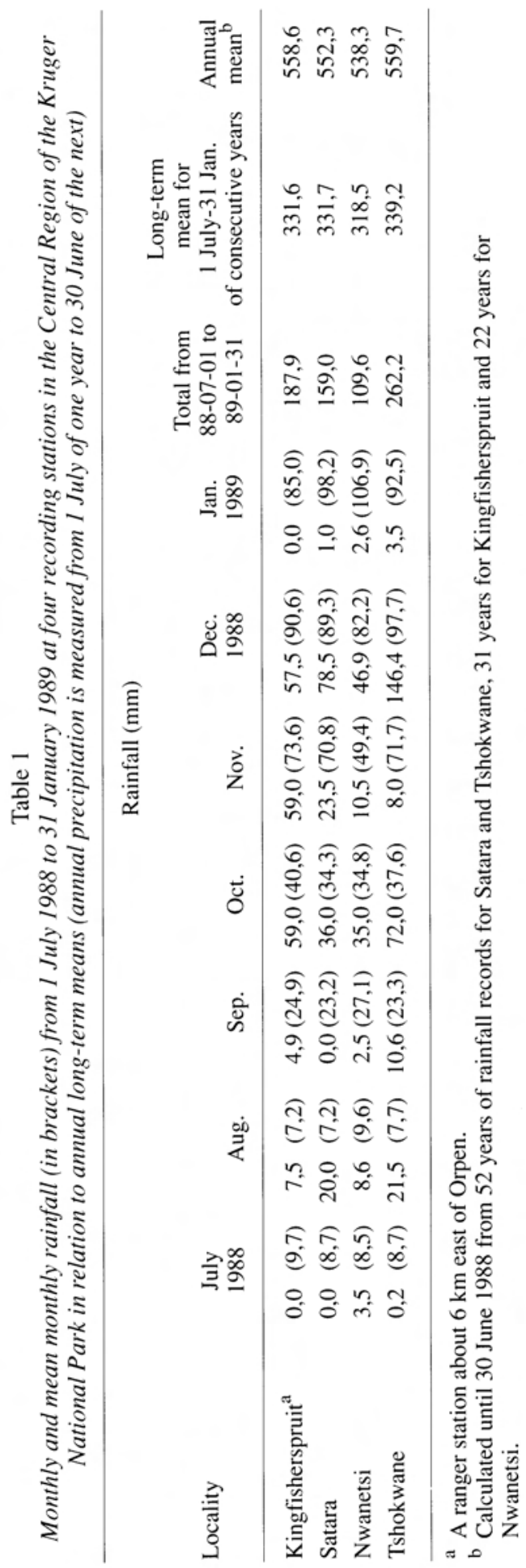




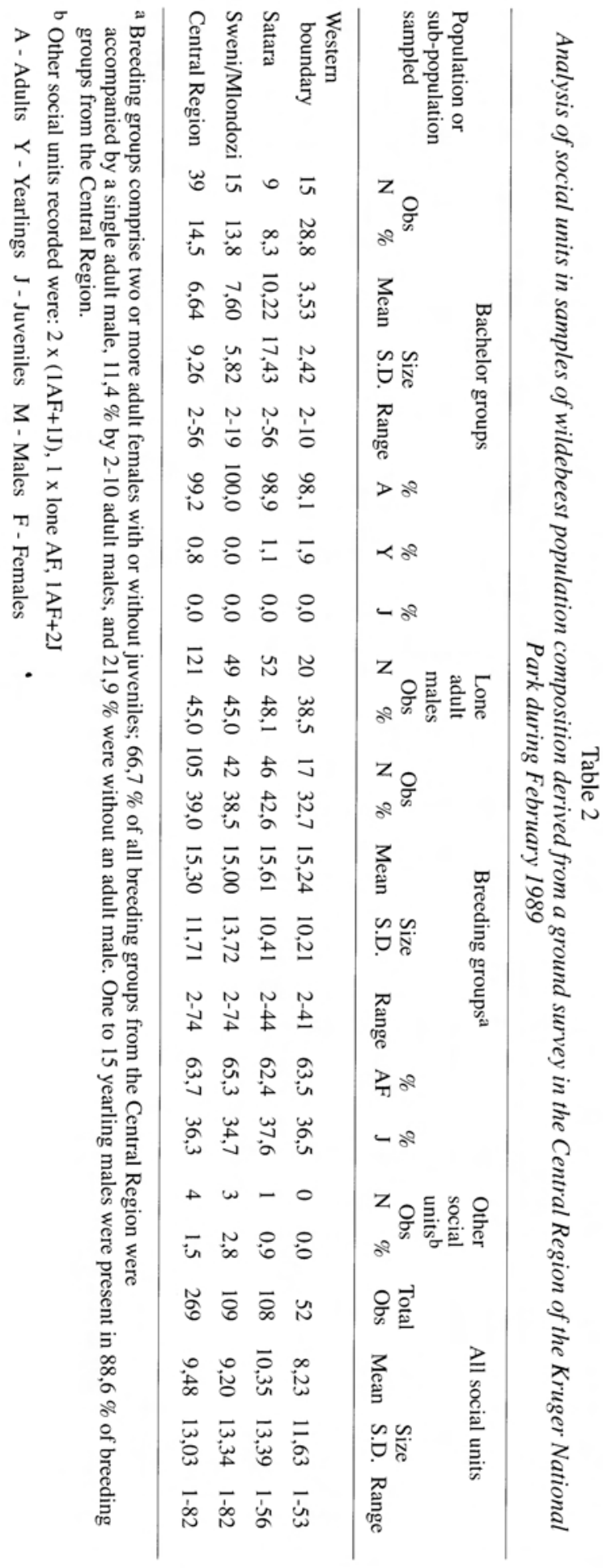




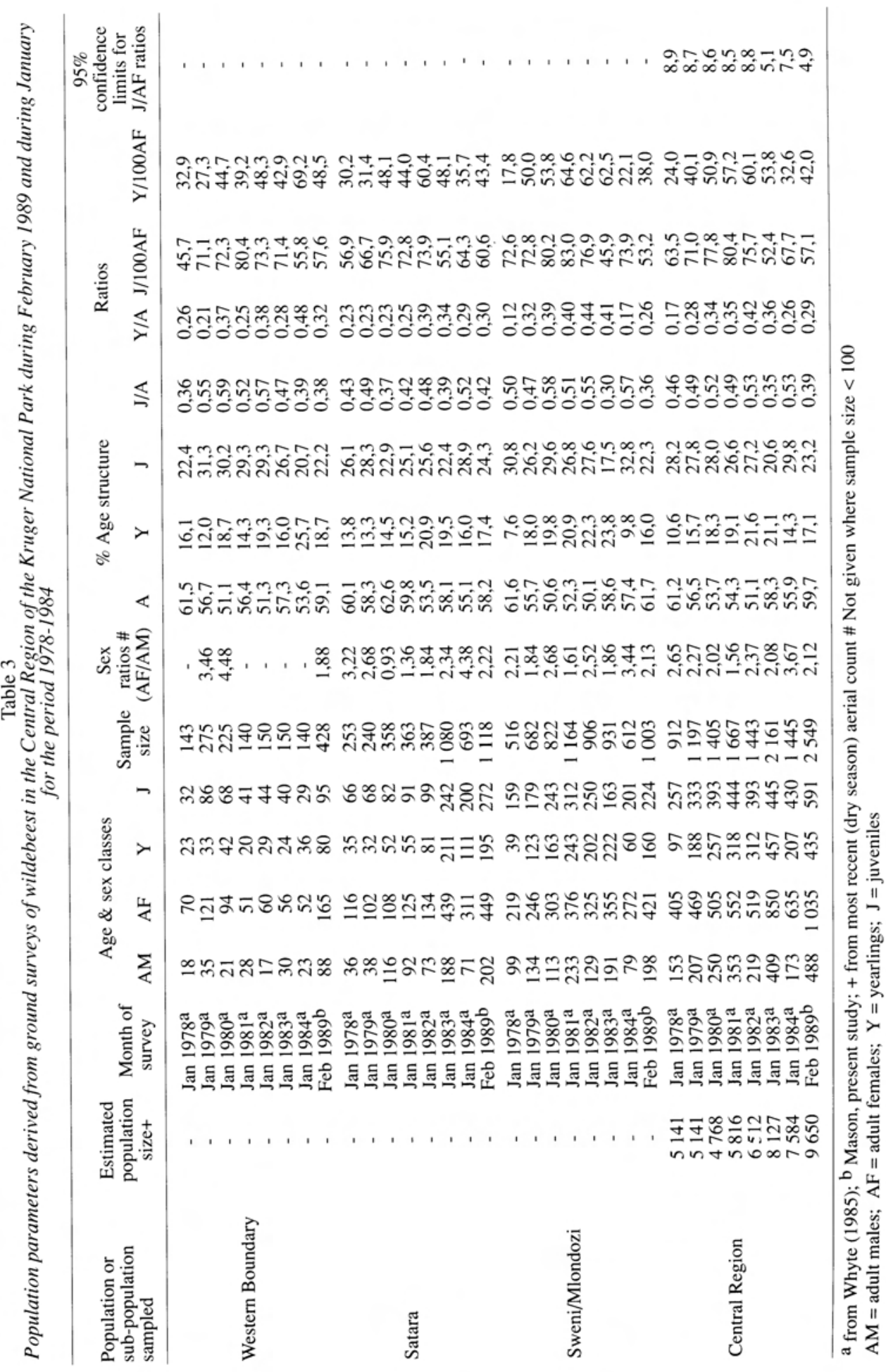


Whyte (1985) found that the proportions of adult males recorded in ground surveys were unreliably variable depending on whether large bachelor herds were encountered or not, thus confounding the usefulness of juvenile percentages as an index of calf survival rates. However, because cows and calves are normally together, there is a more equal probability of recording each during ground sampling of population structure. Moreover, since wildebeest are highly seasonal breeders, changes in the proportion of juveniles to adult females after the calving season may be used as an index of relative juvenile mortality rates. Whyte (op. cit.) found that cow/calf ratios declined sharply after birth so that only data collected at similar intervals after the birth peak were comparable.

Wildebeest population and sub-population characteristics prevailing in the Central Region during February 1989 (this survey) and January 1979-1984 (Whyte 1985) are compared in Table 3. Whyte's data were derived from quarterly ground surveys and are also based on four age and sex classes of wildebeest. Drought conditions during the 1982/83 calving season were associated with a low cow/calf ratio of $52,4 \pm 5,1$ juveniles per 100 adult females in January 1983, when many wildebeest were in poor condition. In February 1989 the survival rate was similar but not significantly different ( $57,1 \pm 4,9$ juveniles per 100 adult females). However, physical condition was generally good, suggesting that the wildebeest population of the Central Region had tolerated the summer drought of 1988/89 better than that of 1982/83.

Little or no difference is evident between the relative survival rates of juveniles in February 1989 and during August-October 1988, notwithstanding the different age ranges of about 1-3 months and 6-11 months respectively for these two successive cohorts of juveniles. A sample of 1569 wildebeest classified in the Central Region during August-October 1988 comprised 22,8\% juveniles, occurring in the ratio of 47,5 juveniles per 100 adult plus yearling females. Although yearling females were not differentiated from adult females, yearling males comprised 7,4 \% of this population sample. Assuming a similar proportion of yearling females, a ratio of about 56 juveniles per 100 adult females may be estimated during August-October 1988. Subsequently, the relative survival of calves from the 1987/88 season declined to 42,0 per 100 adult females in February 1989, when these calves were into their second year (Table 3). This moderate recruitment of yearlings in early 1989 partly offsets the relatively low survival of juveniles recruited in the 1988/89 birth season.

While trends in wildebeest population size for the Central Region are inversely related to rainfall cycles via habitat condition (Whyte 1985; Whyte \& Joubert 1988), Whyte (op. cit.) found no relation between cow/calf ratios when calves were one year old and rainfall, whether from the season prior to birth or during the first year of life. However, he did not examine the influence of rainfall during the first three months of the wet season on early calf survival, which was highly variable. When rainfall during the first half of the wet season (October-December) was plotted (Fig. 2) against percentages of adult cows with calves during January for the years 1978-1984 (Whyte 1985) and in February 1989 (this survey), a significant positive correlation was found $(\mathrm{r}=0,73, \mathrm{p}<0,05)$. The relationship is expressed by the regression equation $\mathrm{y}=48,069+0,104 \mathrm{x}$ where $\mathrm{y}=$ calf/adult cow ratio $(\%)$ and $\mathrm{x}$ $=$ rainfall in mm. In kudu Tragelaphus strepsiceros, Owen-Smith (1984) also found that juvenile survival is closely correlated with rainfall during the period of pregnancy and lactation. Novellie (1986) demonstrated a significant positive correlation between the proportion of bontebok Damaliscus dorcas dorcas lambs surviving at the end of the lambing season and rainfall over the 12 months preceding the mating season. Moreover, Novellie (op. cit.) concluded that the percentage of bontebok ewes with lambs appears to be a good index of the population condition because of its evident sensitivity to changes in food abundance, 


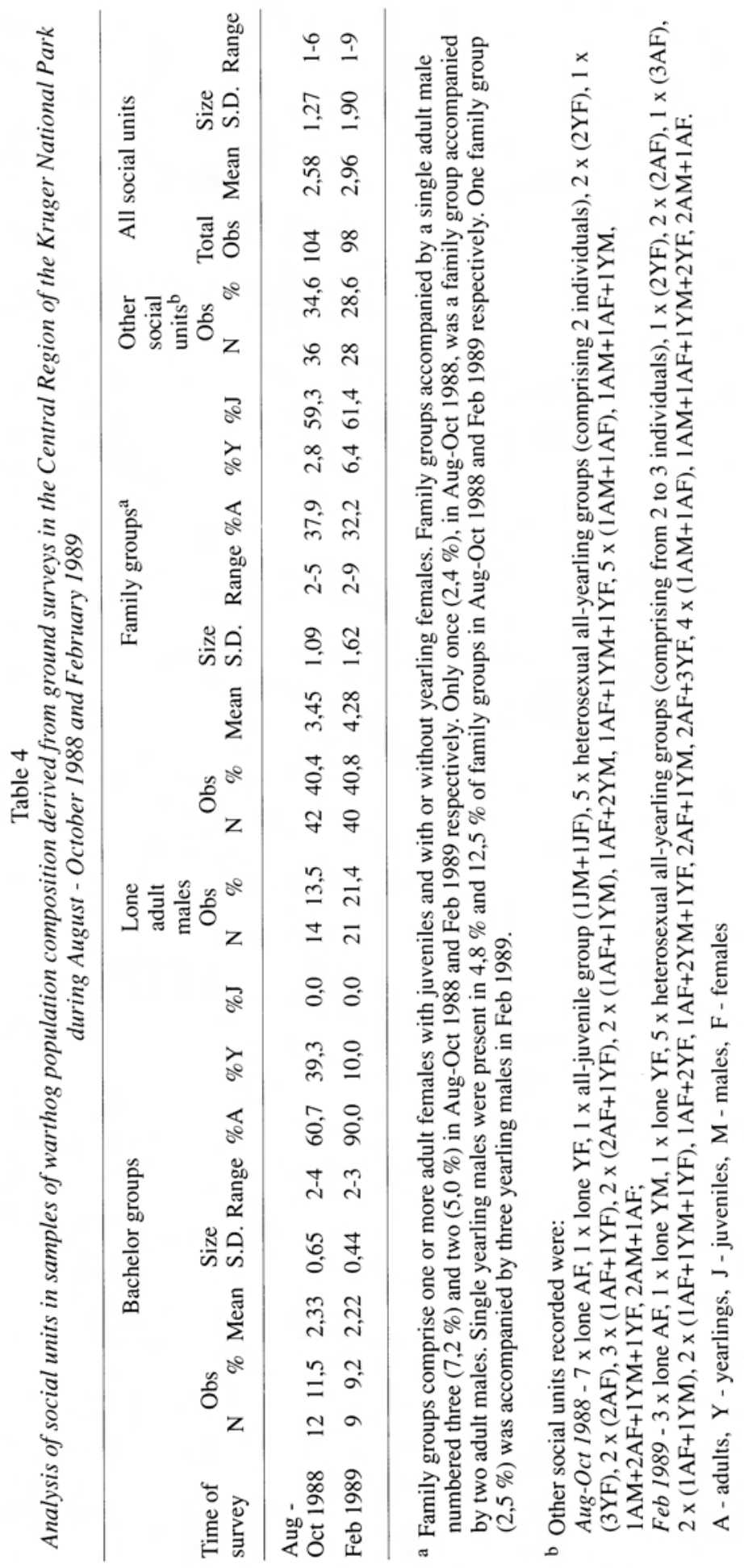


under the influence of rainfall and grazing pressure. With wildebeest in the KNP, however, rainfall influences not only nutrition but also vegetative cover, which in turn may influence vulnerability to predation.

Ratios of juveniles to adult females in February 1989 were lowest in the Sweni/Mlondozi sub-population but exceeded the ratios of yearlings to adult females in all three sub-populations. Juveniles normally outnumber yearlings but deviations can occur as a consequence of differential mortality during drought (Estes \& Estes 1979). Although Whyte (1985) recorded a slight excess of yearlings in the Central Region during January 1983 (Table 3), this probably reflects sampling variation since juvenile/yearling ratios from his subsequent samples during April, July and October of the same year showed a preponderance of juveniles.

Allowing for sampling variability and trends in the annual population cycle, Whyte (1985) found that the sex ratio of adult wildebeest in the Central Region became increasingly skewed towards bulls from 1978 until the pattern reversed after 1981. Reasons for this distortion could include skewed foetal sex ratios in relation to climatic cycles, but data are lacking. Child (1972) found evidence of differential mortality favouring females in most age classes during drought-induced mass mortality of wildebeest in Botswana over three months of the 1970 dry season; juveniles were the first to die in large numbers and suffered disproportionately high mortality. Hillman \& Hillman (1977) noted that drought mortality of wildebeest in Nairobi National Park first involved calves and cows with a greater proportion of cows dying than expected, notwithstanding a mortality rate among adult males that was initially very low but increased towards the end of the drought period.

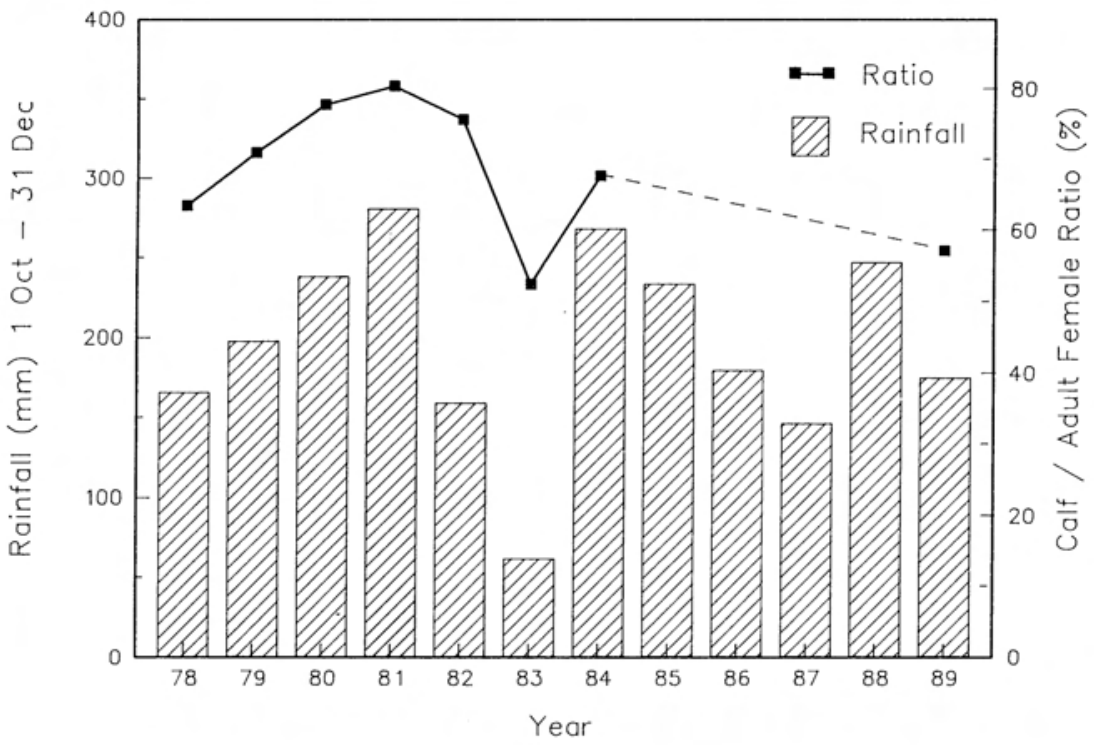

Fig. 2. Relation between early summer rainfall and wildebeest early calf survival in the Central Region of the Kruger National Park (Data from Whyte, 1985 \& Mason, this study) 


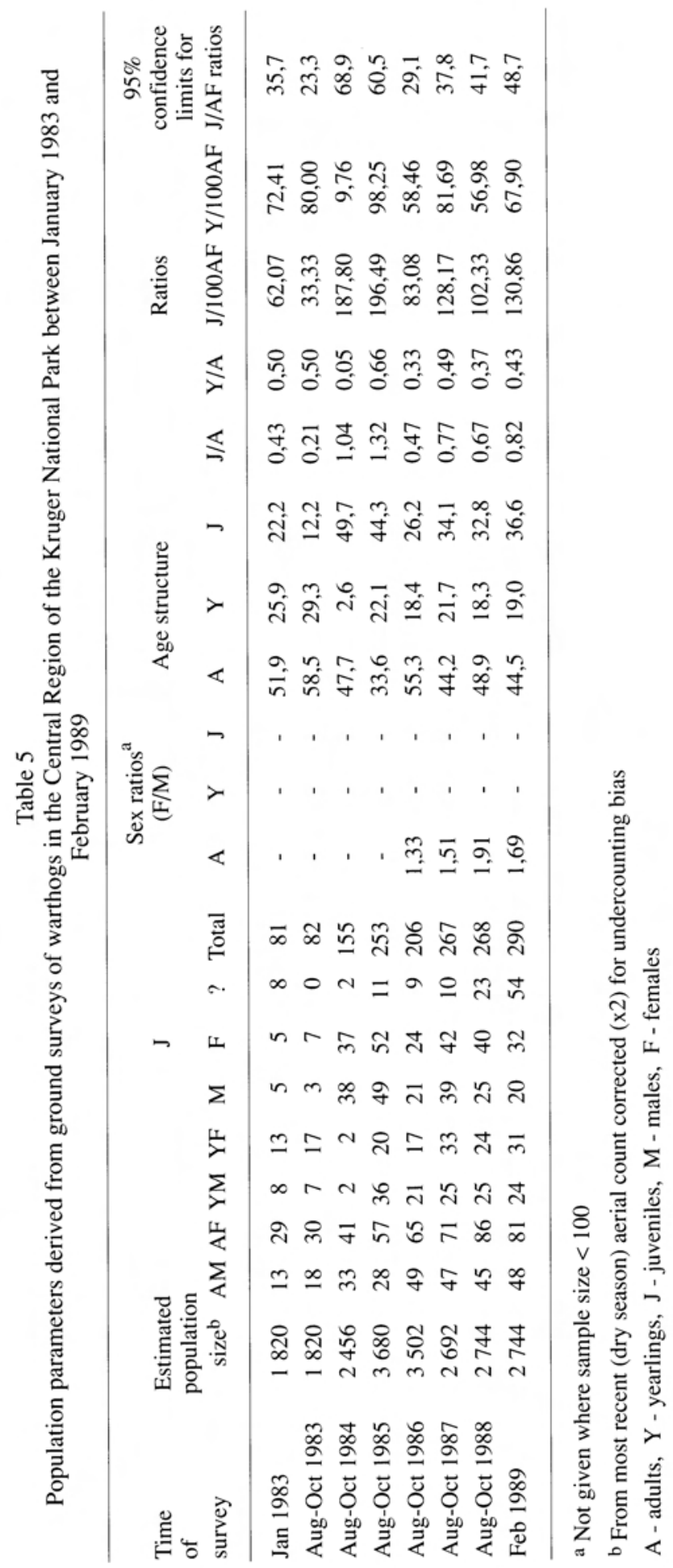


Calf losses much higher than in the Central Region during the 1982/83 and 1988/89 droughts were recorded in Tanzania during 1966 and 1967, when the calving and early post-calving periods of wildebeest from the Serengeti plains and adjacent Ngorongoro Crater also coincided with drought. Watson (1969) estimated that only $21 \%$ of the 1966 calf crop from the Serengeti survived the first few weeks after birth compared with $72 \%$ initial survival in 1963. The full effect of the drought on Ngorongoro wildebeest was delayed until 1967 when Kruuk (1972) recorded only 9,4\% calves during June. In Nairobi National Park, Kenya, calf recruitment in the wildebeest population largely failed during the latter part of the 1973-1974 drought which coincided with the calving season (Hillman \& Hillman 1977). However, very high losses of young in seasonally breeding herbivores during a drought period can be followed by exceptionally large pulses of recruitment resulting from the predominance of mature females in the surviving populations (Walker, Emslie, Owen-Smith \& Scholes 1987).

High variability in juvenile survival rates during the first few weeks of life would immediately affect population size and, after a time lag, the rate of increase via the proportion of female young surviving into their first reproductive year (Watson 1969). However, juvenile survival alone is insufficient to predict population trend which is determined by a composite of factors including yearling and adult mortality rates, pregnancy rates and possibly even variations in sex ratios at birth. High yesarling or adult mortality may negate population growth even though juvenile survival is high, and vice versa. Field classifications of sex and age classes provide no information on adult mortality rates which, if disproportionately high among adult females, may inflate estimates of juvenile survival based on cow/calf ratios. High pregnancy rates have been reported for adult wildebeest in southern Africa (Braack 1973; Attwell \& Hanks 1980), although very variable fecundity for cows in their second reproductive year has been observed in East Africa, both from year to year and between populations (Watson op. cit.). Pregnancy rates vary widely among yearlings, and in the Central Region of KNP have ranged from $11,8 \%$ in 1967 to $57,1 \%$ in 1972 (Braack op. cit.).

Clarification of population trends in wildebeest from the Central Region and throughout the KNP during the remainder of 1989 must await the dry-season aerial census and the ground survey in August-October, when surviving calves approach the end of their first year and constitute potential recruitment into the yearling age class of 1990. (Good rains throughout KNP during February 1989 relieved the drought and the subsequent dry season aerial count of wildebeest in the Central Region was 9547 , an apparent decline of only $1,1 \%$ since 1988 . The 1989 total population count of 13709 wildebeest in KNP represented a 4,2\% decrease.)

\section{Warthogs}

Social units recorded in population samples of warthogs from the Central Region during August-October 1988 and February 1989 are compared in Table 4. As may be expected, mean sizes of family groups (matriarchal sounders) and all social units were larger in February 1989, shortly after the farrowing season in November and December of 1988 . In accord with social dynamics, relatively more family groups were still accompanied by yearling males during February 1989, early in the annual population cycle.

The sex and age structure of warthogs during February 1989 is compared with trends 
from regular field classifications during August-October over the past six years, following a pilot survey in January 1983 (Table 5). These samples are small in relation to the estimated population size, which imposes rather wide confidence limits on the estimates of juvenile/adult female ratios. Although sampling variance has not been determined, the sex ratios recorded for adult warthogs from 1983 to 1989 accord with findings reported for other warthog populations that a preponderance of females is commonly a natural condition (Mason 1982). Large fluctuations in age structure are evident from year to year, particularly between 1983 and 1984 .

Rainfall for the KNP as a whole during the $1982 / 83$ season was only $49 \%$ of the long-term annual mean $(547,7 \mathrm{~mm})$, based on records for 20 stations. These drought conditions were at their worst during the farrowing and early post-farrowing periods, resulting in high neonatal mortality. Some sows probably aborted and there were widespread deaths among adult warthogs due to malnutrition. The 1983 aerial count of 910 warthogs in the Central Region was 39,9\% lower than that of the previous year. By August-October 1983 when there were only 33,3 juveniles surviving per 100 adult females, it was evident that juvenile mortality had largely negated reproductive success in the 1982 farrowing season. This was corroborated by the extreme scarcity of yearlings recruited in $1984(9,8$ per 100 adult females during August-October). Mortality patterns in a declining warthog population marooned on islands in Lake Kariba showed that juveniles were most sensitive to environmental stress, while adult survival was last to be affected (Child 1968). Rainfall in the Central Region improved during the 1983/84 wet season and farrowing at the end of 1983 was more successful with 187,8 juveniles surviving per 100 adult females during August-October 1984. By 1986 the warthog population had recovered.

From an estimated survival rate of 128,2 juveniles per 100 adult females during August-October 1987, recruitment and survival of yearlings was down to 57,0 per 100 adult females a year later. Moreover, juvenile survival in 1988 was mediocre (102,3 per 100 adult females) and, if adult mortality rates remained much the same, was also followed by relatively poor recruitment of yearlings $(67,9$ per 100 adult females) in 1989. The survival rate of 130,9 juveniles per 100 adult females in February 1989, so soon after farrowing at the end of 1988 , is substantially lower than may be expected from the probable reproductive output even if this is conservatively estimated as having been of the order of 200 to 250 juveniles per 100 adult females. In good years the reproductive performance of warthog populations may exceed 300 juveniles per 100 adult females, with most yearling females conceiving at about 18 to 19 months of age (Mason 1982). Thus the warthog population of the Central Region appears to be on the verge of a decline, but this should be smaller than the $39,9 \%$ decrease in 1983 unless mortality rates of juveniles, yearlings and adults are much above average during the remainder of 1989. (The 1989 aerial census totals for warthogs in the Central Region and the KNP were 1043 and 2600 , representing declines of 24,0 and 16,5\% respectively). Even after sharp decreases, warthog populations can recover rapidly because of their high reproductive propensity when conditions are favourable.

\section{Conclusions}

Since normal wildebeest calf mortality may account for approximately half the crop by the end of their first year (Hillman \& Hillman 1977), a drastic reduction in calf 
survival soon after the seasonal birth pulse would not favour population growth. The February 1989 cow/calf ratio recorded for wildebeest in the Central Region (Table 3 ) was sufficiently depressed in relation to estimates for January of more normal years to suggest that a population decline may be imminent. However, while juvenile recruitment in early 1989 was relatively low $(57,1 \pm 4,9$ per 100 adult females), yearling recruitment was moderate $(42,0 \pm 3,5$ per 100 adult females), and the subsequent dry season aerial count was only $1,1 \%$ lower than the 1988 population count, which is too small a difference to indicate a definite downward trend.

Juvenile wildebeest recruitment was $52,4 \pm 5,1$ per 100 adult females in January 1983 and did not differ significantly from early 1989. However, the January 1983 estimate of yearling recruitment ( $53,8 \pm 4,3$ per 100 adult females) was probably biased because subsequent samples during April, July and October of the same year (Whyte 1985) showed proportionately more juveniles than yearlings. Consequently the April 1983 estimate of $30,8 \pm 3,2$ yearlings per 100 adult females, is considered to be a more realistic indication of yearling recruitment in 1983. Compared to 1989, an apparently larger decline of $6,7 \%$ was recorded in the aerial counts of wildebeest in the Central Region between 1982 and 1983. Although calibration of indices of juvenile and yearling recruitment from ground surveys with aerial count trends may be impaired or spurious for various reasons, including movement of animals between aerial census compartments, the 1982/83 drought was more severe in its impact on herbivore populations than that of $1988 / 89$.

Following rainfall in the 1981/82 wet season that was $29,5 \%$ below the long-term annual mean of $550,6 \mathrm{~mm}$ for the Central Region (based on records from four stations), failure of the spring rains in late 1982 induced widespread malnutrition and population declines among most herbivores. Many carcasses of impala Aepyceros melampus, warthogs, buffalo Syncerus caffer and others were found untouched by predators. Rainfall averaged only $61,9 \mathrm{~mm}$ during October-December 1982 and 307,8 $\mathrm{mm}$ (a deficit of $44,1 \%$ ) for the $1982 / 83$ wet season as a whole. Corresponding figures for October-December 1988 and the 1988/89 wet season were $175,3 \mathrm{~mm}$ and $417,9 \mathrm{~mm}$, the latter representing a deficit of $24,1 \%$. However, mean rainfall in the $1987 / 88$ wet season $(620,4 \mathrm{~mm})$ was $12,7 \%$ above average.

Apart from comparatively small-scale mortality among certain herbivores that was attributed to a combination of nutritional stress and exposure during cold, wet weather from 11-13 October 1988, there was no die-off of wildebeest or warthogs during the summer drought of 1988/89. No starvation mortality was recorded among wildebeest during the 1982/83 drought although Whyte (1985) noted that many were in poor physical condition during January 1983, the only time in the six years of his study. Moreover, wildebeest observed in February 1989 were generally in good condition, so it is concluded that the population tolerated the summer drought of $1988 / 89$ better than that of $1982 / 83$. However, conditions during both these drought periods were not extreme enough to cause very high calf mortality $(>80 \%)$ as has been reported in some studies, although such comparisons should also be related to population density, overall biomass and other salient factors. Movements of wildebeest away from drought-stressed areas have been reported (Hillman \& Hillman 1977; Walker et al. 1987) and may enhance survival if not restricted by fences. In the Klaserie Private Nature Reserve along the western boundary of the KNP, the late 1982 drought resulted in wildebeest breaching fences and moving in a largely unsuccessful attempt to escape food depletion (Walker et al., op. cit.)

Warthogs are predominantly grazers favouring short grass but during the dry season 
they adapt their diet to include a much larger proportion of mainly graminaceous plant material shovelled from beneath the soil surface with the snout. The stem bases of some grasses are also selected. In the KNP, grasses favoured by warthogs for their rhizomes include Cynodon dactylon which may form extensive stoloniferous lawns on riparian terraces, and Echinochloa holubii, E. stagnina, Ischaemum afrum and other species that grow in vlei areas and some pans. As foraging habitats, vleis are generally small and of restricted distribution in the KNP. Moreover, warthogs are relatively sedentary so that localised concentrations of rhizomatous forage are only likely to benefit those individuals with home ranges that abut or include such assets. Exploitation of grass rhizomes as well as bulbs, tubers and corms of other plants where available, becomes particularly important to the survival of warthogs during drought when the grass cover over large areas may be reduced to sparse, short stubble due to lack of growth, grazing pressure by ungulates (especially around water sources), and removal by harvester termites (Hodotermes mossambicus).

Notwithstanding the ability of warthogs to dig for sub-surface plant food even in fairly hard soils, the vulnerability of the population in the KNP to drought was evident when the spring rains virtually failed at the start of the 1982/83 wet season. Because this coincided with farrowing and many sows were in poor condition, neonatal mortality was particularly high. Moreover, starvation-induced deaths among adult warthogs were widespread and the $39,9 \%$ decline in the minimum warthog population size estimated by the 1983 aerial census was the sharpest recorded among all the large herbivore populations of the Central Region. In relation to the probable reproductive output, losses of $80-90 \%$ of the 1982 piglet crop were estimated to have occurred during the first year after birth.

Mean rainfall for the months October-December in the Central Region was markedly better in 1988 than in $1982(175,3 \mathrm{~mm}$ vs. $61,9 \mathrm{~mm})$ and the rainfall failure in midsummer of $1988 / 89$ was associated with a smaller decline of $24,0 \%$ in the subsequent (1989) dry season aerial count of warthogs vis-a-vis the $39,9 \%$ decrease recorded between 1982 and 1983. A population decline in 1989 was predicted from the results of the ground survey in February, when the estimated survival rate of 130,9 juveniles per 100 adult females was probably commensurate with early post-farrowing mortality of $35-50 \%$. This reduction in juvenile survival and relatively poor yearling recruitment contributed to the population decline that followed the $1988 / 89$ drought, but unlike the last quarter of 1982, there was no noticeable die-off.

Wildebeest and warthog populations in the KNP can be expected to fluctuate with weather cycles and associated changes in habitat conditions. While wetter cycles induce wildebeest population declines, drier cycles are more favourable and allow a recovery, but extreme drought conditions do not favour wildebeest and can cause very high calf mortality (Whyte 1985). Trends in recruitment gauged by relative survival rates of juveniles and yearlings from population samples were in accord with aerial census trends in indicating that wildebeest tolerated the 1988/89 drought better than that of 1982/83. However, warthogs have a higher reproductive potential than wildebeest and can more rapidly compensate for large population losses once conditions improve.

\section{Acknowledgements}

I wish to thank Messrs. P.F. Retief, P.C. Viljoen and N. Zambatis for computer services, comments and advice on aspects of this paper, and assistance in obtaining weather records. 
WHYTE, I.J. 1985. The present ecological status of the blue wildebeest (Connochaetes taurinus taurinus Burchell, 1823) in the Central District of the Kruger National Park. M.Sc. thesis, University of Natal, Pietermaritzburg.

WHYTE, I.J. and S.C.J. JOUBERT. 1988. Blue wildebeest population trends in the Kruger National Park and the effects of fencing. South African Journal of Wildlife Research 18: 7887.

WHYTE, I.J. and P.C. VILJOEN. 1988. Census results and culling quotas for the larger herbivore species in the Kruger National Park - 1988. Internal report, National Parks Board, Skukuza. Unpubl.

WILLIAMSON, D.T. and B. MBANO. 1988. Wildebeest mortality during 1983 at Lake Xau, Botswana. African Journal of Ecology 26: 341-344.

WYOMING GAME AND FISH DEPARTMENT. 1977. Sample sizes and confidence intervals for wildlife population ratios. Planning Report 6-A, Wyoming Game \& Fish Department, U.S.A. 